\title{
Socio-Cultural Significance of Yerba Maté among Syrian Residents and Diaspora
}

\author{
Naji Sulaiman ${ }^{1}$, Andrea Pieroni ${ }^{2,3}$, Renata Sónkand ${ }^{4}$, Cory Whitney ${ }^{5,6}$, and \\ ZBYNEK POLESNY*,1
}

${ }^{1}$ Department of Crop Sciences and Agroforestry, Faculty of Tropical AgriSciences, Czech University of Life Sciences Prague, Kamýcká 129, 165 00, Praha - Suchdol, Czech Republic

${ }^{2}$ University of Gastronomic Sciences, Pollenzo, Bra, Italy

${ }^{3}$ Medical Analysis Department, Faculty of Science, Tishk International University, Erbil, Iraq

${ }^{4}$ Department of Environmental Sciences, Informatics and Statistics, Ca' Foscari University of Venice, Venice, Italy

${ }^{5}$ Institute of Crop Sciences and Resource Conservation (INRES), Horticulture Institute, University of Bonn, Auf Dem Huegel 6, 53121, Bonn, Germany

${ }^{6}$ Center for Development Research (ZEF), University of Bonn, Genscherallee 3, 53113, Bonn, Germany

${ }^{*}$ Corresponding author; e-mail: polesny@ftz.czu.cz

\begin{abstract}
Socio-Cultural Significance of Yerba Maté among Syrian Residents and Diaspora. Syria is the world's second-largest importer of the dried leaves of Ilex paraguariensis A.St.-Hil., commonly known as yerba maté. The unique story of yerba maté in the Syrian beverage culture started at the beginning of the twentieth century when Syrian migrants returning from South America brought the beverage with them. The overall aim of our study is to understand yerba maté use among Syrians and its role as an essential part of the Syrian beverage culture. We compare yerba maté consumption on spatial, gender, and religious bases through semi-structured interviews with 50 respondents, with equal participation among genders, place of residence, and cultural-religious groups (Sunni, Alawite, Christian, Druze, and Ismaili). We found that the Alawite and Druze groups have the highest yerba maté consumption, and that men drink more than women. Yerba maté was the most preferred stimulant drink among participants, followed by coffee and tea, respectively. Interviews reveal social and cultural factors, perceived addiction, perceived pleasure, and perceived health properties as the drivers behind yerba maté consumption in Syria.
\end{abstract}

Key Words: Ilex paraguariensis, Conflict area, Ethnobotany, Cultural migration, Stimulant plants, Beverages.

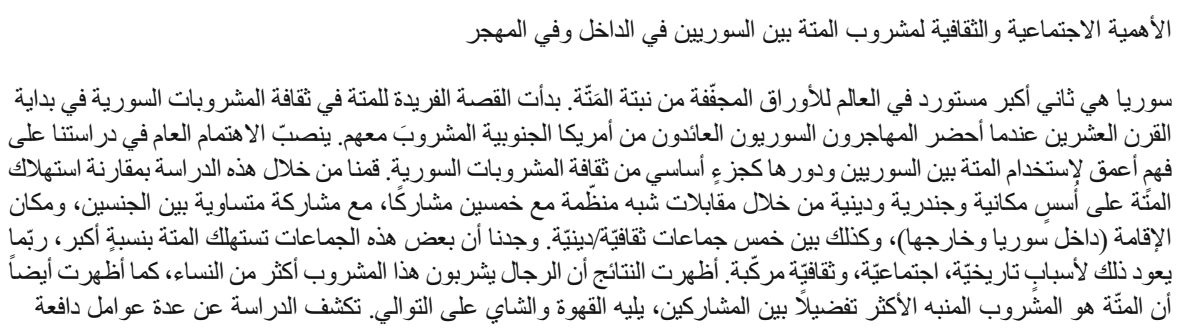

\footnotetext{
${ }^{1}$ Received 24 January 2021; accepted 14 June 2021; published online 10 September 2021

Supplementary Information The online version contains supplementary material available at https://doi.org/ 10.1007/s12231-021-09523-6.
} 
لاستهلاك المنة بين السوريين، يمكن تلخيص هذه العو امل وفق الآتي: العوامل الاجتماعية والثقافية، الإدمان المتصؤر، الكتعة المتصؤرة،

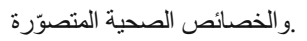

؛ مناطق صر اع؛ علم النبات العرقي؛ الهجرة الثقافية؛ نباتات منبهة؛ مشروبات Ilex paraguariensis الأهمية/لكلمات المفتاحية :

\section{Introduction}

Plant use-related knowledge is impacted by human migration, mainly as a result of adaptation to the new flora of the host country (Medeiros et al. 2012). During the last century, several stimulant plants have traveled into communities that do not traditionally have an association with its consumption. These plants were transported by migrants and refugees who consumed it in the diaspora (Carrier 2007). Yerba maté (Ilex paraguariensis A.St.-Hil., Aquifoliaceae), which was brought into Syria by Syrian migrants returning from South America, is one of those plants. Syria is the world's secondlargest importer of the dried leaves of the plant that is commonly known as yerba maté. In 2018, the country imported 34.5 million kilograms, with an approximate value of USD 71.7 million, which clearly reflects the high demand on this product from the Syrian community (INYM 2019; OEC 2018b). Despite the current hard economic sanctions on Syria, which have affected foreign exchange reserves, the Central Bank of Syria decided in 2019 to include yerba maté among the essential commodities supported for import, along with rice, sugar, baby milk, and medicine, which highlights the significance of yerba maté in Syrian life. However, it is still not entirely clear when yerba maté entered the Middle East for the first time; what is certain is that it took place before 1936. The first record-keeping of Argentinian yerba maté exports began in 1936. At that time, Syria was already the second-largest importer after Bolivia (Folch 2010). Understanding the importance of this foreign beverage among Syrian society could stimulate questions on the agroeconomic possibilities of yerba maté production in Syria. On the other hand, understanding the patterns of and motivations for yerba maté consumption could be informative for finding alternative local beverages, especially since the local flora contains many candidate plants for beverage use such as Micromeria myrtifolia Boiss. \& Hohen. (Obón et al. 2014). This could positively affect the local economy. Additionally, this study fits in the theoretical framework of Traveling Cultures and Plants (Pieroni and Vandebroek 2007) and the study of perceptions and uses of plants that traveled with migrating people, highlighting how plant knowledge changes and evolves.

To trace the roots of the unique Syria-yerba maté relationship, we can look back to the second half of the nineteenth century and to significant events linking the Middle East and Latin America. Between 1881 and 1914, at least 600,000 Arabicspeaking individuals from Syria and Mount Lebanon migrated from the Ottoman Empire to the Americas. Of these, around 400,000 Arabs settled in South America before World War I (Karpat 1985). The majority of those migrants (46\%) settled in Argentina. Starting from the 1870s, an economic boom took place on the continent due to increased demand for Latin America's agricultural products, which resulted in demand for a large labor force. Additionally, political riots, intricate and delicate religious affairs, and religious quarrels were among the motives for Syrian and Lebanese migration (Kukovecz 1995).

While some people were drawn to Latin America due to economic conditions, instability was another motive that drove others away from their homeland. A series of armed conflicts embroiled the Levant from the nineteenth century onwards: the DruzeMaronite Christian conflict in the mid-nineteenth century, the Hauran Druze Rebellion against the Ottomans in 1909, the First World War, the collapse of the Ottoman Empire, the French mandate on Syria and Lebanon in 1923, the Great Syrian Revolt in 1925, the Second World War, the ArabIsraeli War in 1948, the Lebanese civil wars in 1958 and 1975, the Arab-Israeli wars in 1967 and 1973, and the Israeli occupation of Lebanon in 1982 (Bouknight 2018; Fersan 2010). Conflicts in the region are still occurring. In 2011, Syria entered an armed conflict that has caused the largest displacement crisis since World War II: 6.2 million Syrians are internally displaced, and 5.7 million more are registered as refugees outside of the country (WFP 2019). As a result of this continuous, unstable situation, many have migrated to safer places, with South America being one of the leading 
destinations. Over time, migrants have become rooted in their new home and have adapted to the new culture. Some of them have become notable personalities, such as Carlos Menem, the former Argentinian president (1989-1999). Some of the returning Levantines brought yerba maté to Syria, Lebanon, and parts of northern Palestine in the early twentieth century (Fersan 2010; Yerba Maté Argentina 2020).

Religious minorities represent the majority of Levantine migrants due to the previously mentioned reasons and highlighted historical events, as well as the discrimination and persecution they suffered under Ottoman Empire control, represented mainly by religious "Fatwas" that were issued against Ismailis, Nusayris (Alawites), and Druzes (Talhamy 2010). The religious spectrum in Syria mainly consists of Sunnis, Alawites, Christians, Druzes, and Ismailis, which constitute the following percentages of the Syrian population: $74 \%, 12 \%$, $10 \%, 3 \%,<1 \%$, respectively (Lesch 2005). However, those groups do not represent the overall diversity of Syrian society, which also consists of Arabs, Kurds, Assyrians, Armenians, Turkomans, Circassians, Chechens, Jews, Albanians, Greeks, and Yazidis. All those ethno-religious groups have mutually influenced each other over centuries, and they share almost the same socio-economic, political, and cultural realities. However, cultural differences are common, especially in food and beverage habits, which can be drawn along religious lines according to Grigg (2002) for coffee and tea consumption in different societies where religious background had a significant influence. According to Folch (2010), yerba maté is particularly associated with the Druze community in the Middle East, which could possibly be due to Druzes being among the first migrants from the Middle East to South America. However, according to the first author's observations, nowadays, yerba maté is widely consumed among different religious groups. Yerba maté has served as a companion to Syrians for more than a century. It contributed to their successful adaptation to South American culture upon their arrival as foreigners in the early twentieth century. The plant also occupied a place in their travel bags when they returned to their homeland. It has been a part of their daily life for a century, and when the war started, conflicted parties held guns in one hand and yerba maté cups in the other. Yerba maté is commonly consumed during discussions of matters concerning the current conflict and the country's political future. Moreover, when Syrians had to escape from war zones to safer countries, they did not forget to bring yerba maté with them.

We set out to understand yerba maté use among Syrians and its role as an essential part of the Syrian beverage culture. We particularly aim to know why informants drink yerba maté, and to compare yerba maté consumption across several Syrian groups as well as spatial, gender, and religious bases. Another aim is to comprehend the current position of yerba maté among the other stimulant drinks in the country. Additionally, we aim to explore the potential change in yerba maté consumption resulting from the social restrictions of COVID-19, recent post-conflict migration, and economic difficulties.

\section{Methods}

\section{Data Collection}

Study participants were selected using the purposive snowball sampling method (Bernard 2002; Dolores and Tongco 2007) starting from the first author's contact network as a source of informants. When considering potential informants for participation in the study, the basic criterion was that they drank yerba maté at least once per month. We chose informants on a religious basis in order to make a comparative analysis between the cultural differences of those groups regarding yerba maté consumption and to trace the roots of these potential differences. We targeted informants from different social backgrounds, and all levels of education. The 50 total informants were equally represented by men and women. The age of informants ranged between 21 and 70 years. The participants were equally divided into two groups: the first of these included Syrian residents who were chosen from different regions. Out of the 14 total provinces in Syria, 11 were covered by informants sampled in this study. The second group of informants included Syrian diaspora members in 12 countries of Asia, Africa, Europe, and North America. Ten informants $(5$ Syrian residents +5 Syrian diaspora members) from each of the five different culturalreligious groups (Sunni, Alawite, Christian, Druze, Ismaili) were sampled. However, due to limitation in sample size, the sample cannot be considered representative of any part of Syria or the nations with Syrian emigres.

Ethnobotanical surveys were conducted during July and August 2020 through individual in-depth 
semi-structured interviews (Martin 2014). The majority of informants ( 47 out of 50 ) were interviewed remotely, and three were interviewed in person. Informants were asked about their yerba maté consumption patterns, including frequency, ways of and reasons for drinking yerba maté, its perceived health benefits, social and psychological impact, the longest period of time that they could go without drinking yerba maté, and current position of yerba maté among other stimulant beverages. Participants from the diasporas were additionally asked to report changes in their yerba maté consumption since they left Syria, while Syrian residents were asked about the impact of the recent economic difficulties on their yerba maté consumption. We also discussed with all participants changes in yerba maté consumption resulting from social restrictions due to COVID-19 and the history of yerba maté introduction into Syria. All interviews were conducted in the Arabic language. The Code of Ethics of the International Society of Ethnobiology (ISE 2006) was rigorously followed, and informed consent was obtained prior to interviews.

\section{Data ANALYSIS}

The comparison on spatial, gender, and religious bases was conducted, mainly, through calculating the frequency of yerba maté consumption by asking, How often do you drink yerba maté? The answers were calculated on a weekly basis (e.g., the answer of once per day was calculated as seven times per week). One count (one session) of drinking yerba maté is considered the process of infusing dried roasted leaves in a cup, regardless of how many times the glass is refilled with hot water or how much time is spent in drinking. Nevertheless, drinking yerba maté differs from person to person, but commonly takes more than an hour, and includes nearly half a liter of yerba maté infusion.

To determine the position of yerba maté among other stimulant beverages, we asked informants to rank all beverages starting from the most preferred to the least preferred. Since only three beverages were reported, three points were given to the top-ranked drink, two points to the second, and one point to the third-ranked beverage (Martin 2014).

To understand the popularity of this drink in the beverage culture, we asked informants about their reasons for drinking yerba maté, and those reasons were categorized into groups through inductive thematic analysis (Braun and Clarke 2006). Each reason was considered a report; when an informant reported more than one reason within the same category, all such reasons were considered as one report. Answers concerning the perceived health properties of yerba maté were also counted as reports: each answer was considered a report and some informants stated several reports. We used the tools in RAWGraphs software (Mauri et al. 2017) to illustrate trends and differences between the groups of informants.

We used our previously collected data in Syria to support and interpret the qualitative data regarding herbs commonly used as additives to yerba maté (Electronic Supplementary Material [ESM] Appendix 1). The previous data were collected in 2018 from 42 informants who were interviewed about medicinal herbal teas, as well as in spring 2020 from 50 informants who were interviewed about the use of wild plants.

\section{Results}

\section{Syrian Method of Yerba Maté Preparation}

All respondents reported that they buy yerba maté from local shops in Syria and specialized Levantine/Middle Eastern shops abroad. The majority of respondents reported that they prefer the medium or loose kind of yerba maté because it tastes better and sweeter, whereas only $4 \%$ of respondents reported that they prefer the soft kind of yerba maté because it has a heavier taste and it lasts longer until it is washed out (taste becomes too weak). The soft kind of yerba maté is the same as the loose one but ground to smaller pieces, which makes the beverage more concentrated and heavier in taste. The drink is served in different ways in various locations. In most cases, it is consumed as a group activity. It is typically served in small glasses with an approximate volume of $100 \mathrm{ml}$. Such yerba maté is prepared by filling almost half the glass with dry roasted leaves of yerba maté (around $10 \mathrm{~g}$ ), placing the straw (bombilla or bomba in Spanish, massasa in Arabic) in the glass; the 12-15 cm long straw consists of a metal or cane tube that terminates with a perforated filter on the end that is inserted into yerba maté, which allows one to drink the infusion free of pieces of yerba maté leaves. Cold water is first added to yerba maté to steep the leaves. Subsequently, this water is discarded and hot water 
is added to infuse the yerba maté leaves. Drinking starts immediately, and sugar, honey, and/or medicinal herbs are added according to preference. The process of drinking and refilling cups is repeated for $1 \mathrm{~h}$ or more, using approximately half a liter of hot water, until the yerba maté becomes completely washed out.

\section{The History of Yerba Maté Use in Syria}

Despite yerba maté being an everyday drink for most informants, $60 \%$ of them did not possess any information about this plant and the history of this beverage in Syria. Some respondents had the understanding that yerba maté is a traditional Syrian drink. Informants who come from the provinces of Tartus and As-Suwayda as well as Salamiyah and Qalamoun districts demonstrated certain knowledge about the history of yerba maté in Syria. The obtained data suggest that yerba maté culture was initially spread by the people of those areas to other regions within the country and possibly to the whole Middle East. Answers with respect to the date of yerba maté introduction to Syria ranged between 1920 and 1960.

The following quoted responses illustrate the perspective of some participants regarding the first entrance of yerba maté into the country.

"My grandfather went to South America in 1915 in order to escape from the First World War, he returned from Argentina in 1938, bringing with him a big bag (around 50 kilograms) of yerba maté, I think it was the first time that yerba mate entered our village," stated a 49-year-old man.

"Yerba mate entered my region at the beginning of the twentieth century through some of the expatriates in Venezuela, and later it became a popular drink and one of the main types of hospitality in the event of a visitor coming and called it The Duty Cup," a 30-year-old informant reported.

\section{Religious, Spatial, and Gender Comparison of Yerba Maté Consumption}

The frequency of drinking yerba maté among our participants varied between three to five times per day (six reports) and once per month (five reports). Two-thirds of respondents drank yerba maté between 7 and 14 times per week (one or two times per day). Alawite and Druze communities demonstrated the highest weekly consumption of yerba maté, followed by Ismaili, Christian, and Sunni groups, respectively. Variation in consumption frequency was the highest among the Alawite group members, while the least variable consumption frequency was among the Ismaili group (Table 1).

Yerba maté consumption among the Syrians in the diaspora was lower than that among the Syrian residents. This was especially true for the Alawite group, where average consumption for residents was almost four times higher than in diaspora (Fig. 1). Christian and Sunni groups demonstrated a lower difference in their consumption. In contrast, Druze and Ismaili showed the highest similarity in yerba maté consumption regardless of place of residence. According to our results, men drank yerba maté more often than women (Table 1). Figure 1 shows a clear difference in consumption between genders mainly among Christians and Alawites.

\section{Preference Ranking of Stimulant Drinks}

According to the stimulant beverage ranking by informants, yerba maté was the most preferred beverage among study participants, followed by coffee and tea. Coffee was reported as the most preferred by $60 \%$ of Sunni participants, while yerba maté was favored by Alawite, Druze, Christian, and Ismaili participants, with $60 \%, 70 \%, 40 \%$, and $70 \%$, respectively.

\section{Reasons for Drinking Yerba Maté}

There were 73 reports of reasons given for drinking yerba maté, which we categorized into four groups. The category "Social and cultural reasons" comprised $49 \%$ of the reports. This included responses such as, Because it is a popular drink, Because it is a habit, Because it is a traditional drink, and Because it accompanies my meetings with friends and family. The category "Perceived pleasure" formed $25 \%$ of responses; answers in this category were mainly phrased as "recreational" by informants; which, as explained by the participants themselves, means that yerba maté helps them spend time in a joyful manner and with happiness. The category "Perceived addiction" comprised 16\% of informant 
Table 1. Frequency of Drinking Yerba Maté among Different Categories of Participants.

\begin{tabular}{lllll}
\hline \hline Category & Number of respondents (N=50) & \multicolumn{2}{l}{ Weekly frequency of drinking yerba maté } \\
\cline { 5 - 5 } & & & Range & Mean \\
\hline Place of residence & Syria & 25 & $1-35$ & 11.8 \\
\multirow{4}{*}{ Gender } & Diaspora & 25 & $0.25-21$ & 7.21 \\
& Male & 25 & $0.25-35$ & 10.7 \\
Cultural-religious group & Female & 25 & $0.25-21$ & 8.31 \\
& Sunni & 10 & $0.25-14$ & 4.95 \\
& Alawite & 10 & $0.25-35$ & 12.5 \\
& Christian & 10 & $0.25-14$ & 7.85 \\
& Druze & 10 & $4-21$ & 12.4 \\
& Ismaili & 10 & $7-14$ & 9.8 \\
\hline
\end{tabular}

reports, where "addiction" was stated as such by participants. Finally, the "Perceived health properties" category formed $10 \%$ of reports.

Some informants explained from their perspective what yerba maté means to them, and why they drink this beverage.

For instance, a 29-year-old man, currently in the Republic of the Congo, stated:

"I drink yerba maté because of the addiction. If the time passes 15:00 without me drinking it, I cannot concentrate anymore, and I get a headache, and my thoughts become blurred. But when I drink yerba maté, after that I feel that my head goes back to normal. I have an emotional connection to yerba maté; it brings back memories of when I was in Syria, having a picnic under the olive trees with my cousins. I also remember mornings when I used to sit with my father and drink yerba maté with him. yerba maté drives me to nostalgia, and it makes me feel more at home while I am abroad. I taught my foreign friends to drink yerba maté; here I drink yerba maté once or twice a day, but when I was in Syria, I drank yerba maté 4 times a day."

While a 60-year-old woman living in Syria stated:

"Yerba maté for me is like something that exists in my blood. Drinking yerba maté serves as an entertainment activity, it gathers people,

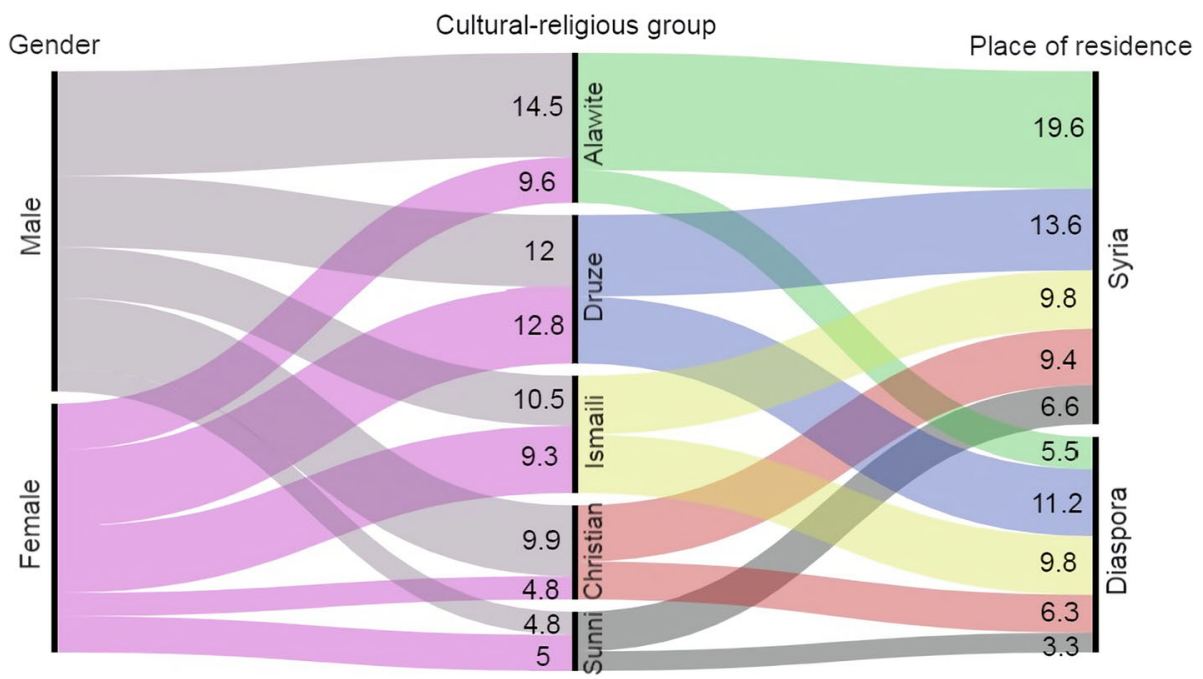

Fig. 1. Yerba maté consumption among religious groups according to gender and place of residence (numbers within the streams refer to the average frequency of yerba maté drinking per week for each category). 
and talks become longer and more pleasant with this beverage. Usually, I combine yerba maté with salty nuts and cigarettes; it makes me feel comfortable, it gives me the feeling of getting high, relaxing my nerves after hearing the war news. I am addicted to yerba maté. In 2014 , when yerba maté disappeared from the market after the highways got cut due to the war, I was looking to buy it even by the half ounce."

\section{Perceived Health Properties of Yerba Maté}

While only $10 \%$ of informants considered health properties as a primary driver of their yerba maté consumption, $86 \%$ of informants perceived yerba maté to have beneficial health effects when asked, Do you find yerba maté to be good for your health? Participants conveyed 82 health-benefit reports of yerba maté corresponding to 14 different medicinal uses (Table 2). Psychological benefits (concentration, calming, and stimulation) were the most cited with 26 reports in total, while urinary tract-related issues (kidney stones, urinary inflammation, and diuretic) were the second most frequently cited with 22 reports in total. Twelve informants reported that yerba maté serves as a good substitute for water and it hydrates the body. According to some participants' statements, yerba maté has helped them with

Table 2. Ethnomedicinal Uses of Yerba Maté AMONG STUdy PARTICIPANTS.

\begin{tabular}{ll}
\hline \hline Medicinal use & $\begin{array}{l}\text { Frequency } \\
\text { of citation } \\
\left(\mathrm{N}_{\text {reports }}=82\right)\end{array}$ \\
\hline $\begin{array}{l}\text { Protection from and treatment } \\
\text { of kidney stones }\end{array}$ & 18 \\
Help to concentrate & 15 \\
Provide hydration & 12 \\
Calming & 9 \\
Treatment of digestive and & 6 \\
$\quad$ intestinal disorders & \\
Treatment of pharyngitis & 4 \\
Slimming & 3 \\
Treatment of cold and flu & 3 \\
Treatment of constipation & 2 \\
Treatment of headache & 2 \\
Treatment of stomachache & 2 \\
Stimulation & 2 \\
Protection against urinary inflammation & 2 \\
Diuretic & 2 \\
\hline
\end{tabular}

some specific health issues; for instance, a 30-yearold man stated:

"I got paralyzed during a battle in the war, and, consequently, I have a urinary catheter. The doctor recommended that I keep drinking liquids from time to time during the day in order to let my kidneys work continuously, which will prevent inflammation from occurring in the urinary catheter. Therefore, I use yerba maté for this purpose."

\section{Yerba Maté, Smoking, and Potential ADDICTION}

Yerba maté consumption is often associated with smoking, and yerba maté consumption itself is considered an "addiction" by some of our informants. While we were piloting the questionnaire (ESM Appendix 2), several informants mentioned that they combine smoking tobacco (cigarettes or shisha) with yerba maté; therefore, we asked the question, Does your smoking increase while drinking yerba maté? A high positive relationship between smoking and drinking yerba maté was found among smokers (21 out of the 50 total informants). The majority of smokers (86\%) reported that their smoking increases during yerba maté sessions.

On the other hand, assessing addiction is a complicated process, especially given the fact that a person could be addicted without knowing it. However, the ability to abstain from consuming a specific substance serves as an important indicator for measuring addiction (Pohler 2010). In addition to the $16 \%$ of informants who perceived themselves to be "addicted," we assessed potential addiction/ dependence by analyzing all informant answers to questions addressing the maximum period they could go without drinking yerba maté. We received a wide range of answers that varied between $2 \mathrm{~h}$ and an unlimited time. The majority of informants $(62 \%)$ reported that they could withstand not consuming yerba maté for up to 1 week. However, there was no apparent difference between Syrian residents and the diaspora regarding the maximum period of abstaining from drinking yerba maté. The majority of respondents who declared perceived addiction as a primary reason for drinking yerba maté could not go more than 2 days without having the beverage, and most of their answers fell in the range of only a few hours. 


\section{Social Impact of Yerba Maté}

Yerba maté is a social drink characterized by the joy of gathering in one place and sharing the same water pot, sugar bowl, salty nuts, sweets, and sometimes even the same cup. Only $14 \%$ of all informants reported drinking yerba maté from the same cup. These informants come from the same province (As-Suwayda) and belong to two religious groups (Druze and Christian); some of them live abroad and others in Syria. Drinking from the same cup is done by sitting in a circle. After one person drinks from the cup, they clean the straw with a piece of lemon, and then the cup is refilled with water and passed to the person on the right. However, $86 \%$ of informants reported that each person has their own cup of yerba maté, but they share the same drinking equipment (water pot, sugar bowl, as well as other snacks and additives).

All informants agreed that they like to drink yerba maté in a group, and some informants mentioned that they do not drink it at all when they are alone. The vast majority of respondents (90\%) reported that yerba maté contributes to gathering with friends and relatives. Many informants mentioned that yerba maté creates a unique atmosphere for long talks, and that it provides a sense of familiarity and integration within the group. Here, we quote what some informants stated:

"Meeting with a group is perfect when yerba maté is present. Without yerba maté, I feel that something is missing. It creates an atmosphere for long meetings."

"It contributes to the closeness of group members as they are around it, sharing the same water pot and sugar bowl. It contributes to long sessions and talks."

"Yerba maté brings about an atmosphere of familiarity, companionship, and reassurance. We feel that the session will be longer just for mentioning (Let us drink yerba maté)."

"Yerba maté creates a suitable atmosphere for spending more time with others, as it takes a longer time to drink, compared to coffee or tea. The conversation over yerba maté lasts longer, and the drink yields a kind of intimacy since the group is involved in doing the same thing during the conversation."

\section{IMPACT OF WAR, COVID-19, AND Migration on Yerba Maté Consumption}

Considering that yerba maté is an imported commodity, it has always been affected by the U.S. dollar (USD) exchange rate to the Syrian Pound (SP), which has frequently changed since the beginning of the conflict in 2011. Nowadays, one package of yerba maté $(250 \mathrm{~g})$ costs around SP 2,500 (almost USD 1.00), while its price was SP 25 (USD $0.50)$ before the war. Due to the lack of available official data, the continuous change in the exchange rate and the value of the currency, and consequently the change in purchasing power, it is difficult to determine the average salary in Syria in USD. It may be estimated to be SP 149,000 per month (Salary Explorer 2020), which equals USD 119 according to the official exchange rate and USD 60 according to the market exchange rate in late October 2020. Yerba maté has frequently become monopolized by traders in order to secure a higher price, while many times during the war it was unavailable in markets because of movement restrictions due to the battles around Yabroud-Rural Damascus, where the factory packaging imported yerba maté is located. Due to all the abovementioned reasons, $48 \%$ of study participants living in Syria have decreased their yerba maté consumption in recent years. In contrast, $52 \%$ of participants reported no change in their consumption, emphasizing that they try to afford yerba maté despite the current conditions, either by storing it or by prioritizing it over other goods. In this regard, some of our informants mentioned that they add other plant species to yerba maté, which function as medicinal herbs and/or partially substitute an amount of yerba maté as a saving method. Most of these herbs are wild gathered plant species, while the rest are cultivated in home gardens or purchased from local markets (ESM Appendix 1).

Besides war conditions, which caused a decrease in yerba maté consumption, migration has also had an influence. More than half (52\%) of the respondents who live abroad reported no change in their yerba maté consumption levels after moving abroad, in spite of the change in lifestyle associated with integration into a new society. On the other hand, $40 \%$ of informants reported a decrease in their yerba maté consumption after immigration, whereas $8 \%$ reported an increase. Lack of time, the nature of a fast lifestyle abroad, and lack of socializing needed for yerba maté sessions were the most 
frequently mentioned reasons for the decrease in yerba maté consumption.

Moreover, a decrease in yerba maté consumption has been noted due to the lack of socializing following COVID-19-related restrictions. Two-thirds of respondents declared a change in their yerba maté consumption and rituals connected with this drink. The change is represented by a decrease in group consumption, or at least being highly cautious by sterilizing the bombillas, drinking from separated cups, and reducing socializing with relatives and friends to the lowest possible level. Conversely, many have reported that their consumption due to COVID-19 restrictions has increased but in the form of individual consumption, especially during curfew periods when a person has to spend a longer time at home, which they feel the need to fill with some activity. However, most respondents showed a tendency to prefer drinking yerba maté in a group but within the same household, arguing that yerba maté is more enjoyable when it is shared with others.

\section{Discussion}

Socio-Cultural Importance of Yerba Maté WITHIN SYRIAN SOCIETY

The socio-cultural importance of stimulant plants has been shown in earlier studies. According to Carrier (2007), consumption of khat (Catha edulis (Vahl) Endl.) in Yemen and Ethiopia is associated with contemplation, conversation, and relaxing in the company of friends, while it reinforces cultural identity and acts as a social adhesive for many among displaced communities. In our study, almost half of informants' reasons for drinking yerba maté were social and cultural, emphasizing the essential social value of this beverage among the study participants. The contribution of yerba maté to gathering with others can be attributed to the atmosphere associated with the way this beverage is consumed and served; this is due to yerba maté being shared as an activity among its drinkers who repeatedly drink and refill glasses with water, share sweets or salty nuts, smoke, and have a discussion simultaneously. Bracesco et al. (2011) have highlighted the social use of yerba maté among South American societies, considering that yerba maté has connotations similar to those of the tea ceremony in some Asian cultures. The daily lifestyle of Syrian people plays a potential role in yerba maté consumption being a habit. Almost one-third of the labor market in Syria is employed in state-owned jobs (Aïta 2009), which are usually not considered strict jobs by many Syrians. They officially start at 8:00 and end at 15:00, but many employees actually leave at 13:00 or even earlier. This free time is often filled by drinking yerba maté. At governmental institutions it is possible to find several employees gathered around a table full of yerba maté glasses. Daily workers in agriculture, construction, and handcrafts also commonly spend their midday breaks drinking yerba maté. Additionally, the ongoing conflict and its daily news update have created a social pattern, where people gather every day around yerba maté cups and discuss the latest news. However, we believe that drinking a beverage as a habit plays a significant function in its widespread presence in some societies. Offering a specific beverage to visitors, as is the case with the yerba maté drink in many areas of Syria, does not necessarily mean that all visitors prefer this beverage, but rather could indicate that the drink is popular and traditional in the region. Furthermore, potential addiction is a crucial factor in the popularity of yerba maté. Young yerba maté leaves contain $0.8-0.9 \%$ caffeine, and in smaller amounts of caffeic and chlorogenic acids, which stimulate the central nervous system, reduce sleepiness, and increase vigilance. Caffeine meets all the requirements for being an addictive substance, including dependence, tolerance, and withdrawal. The symptoms of addiction include nervous irritability, generalized anxiety, and depression (Pohler 2010). That is what we observed in many informants' statements when they described the time they spent without drinking yerba maté. However, many did not perceive caffeine as addictive, or many did not know that they could be potentially "addicted"/dependent on yerba maté, as was demonstrated by informants' reports in which only $16 \%$ openly stated that they are "addicted," from the total of $62 \%$ who could not go longer than a week without drinking yerba maté. On the other hand, $46 \%$ of informants who cannot tolerate 1 week of not drinking yerba maté did not realize that they are potentially dependent. However, due to the limitation in the study sample size, potential addiction/ dependence among our study informants cannot be generalized to all yerba maté consumers in Syria. An additional potential reason behind yerba maté consumption is its association with tobacco smoking. A strong relationship between caffeine consumption and smoking was previously reported by Swanson 
et al. (1994), in agreement with our findings that tobacco smoking increases with yerba maté consumption.

When discussing beverage-related social aspects, the current global pandemic must be taken into consideration. COVID-19 has shaken the social, economic, cultural, and religious bases of human life (Vandebroek et al. 2020). Yerba maté culture has been significantly impacted by the pandemic, especially since yerba maté is characterized as a social drink. Despite the change reported by two-thirds of informants in their yerba maté consumption and its rituals, the majority have quickly reacted to the new restrictions and tried to adapt by following several techniques. These techniques are represented mainly by balancing between social distancing and hygiene recommendations, and the social nature of yerba maté rituals. Methods, such as limiting large group meetings, and careful equipment sterilization, enable people to continue yerba maté consumption despite pandemic-related restrictions and health concerns.

The social impact of yerba maté could be considerable in the post-conflict period. In the times of division that resulted from the almost 10-year armed conflict, yerba maté has remained a mutual habit among millions of Syrians. Nowadays, this beverage occupies a place in cafes, meetings among friends, family gatherings, photos on social media, Syrian TV drama series, and even on battlefields. We believe that this drink, as a social habit, could play an indirect role in healing social wounds in the post-war period, when Syrians will sit down and try to find their cultural points of connection as a basis for their shared future.

\section{Health Properties of Yerba Maté}

Several health benefits perceived by our study participants have been reported elsewhere in the literature, including increased concentration (Glade 2010), calming effect (de Souza et al. 2018), protection against and treatment of kidney stones (Yasir et al. 2018), treatment of several digestive and intestinal disorders (Gorzalczany et al. 2001), slimming and weight loss (Arçari et al. 2009; Gambero and Ribeiro 2015), stimulation effect (de Souza et al. 2018), and diuretic activity (Görgen et al. 2005; Heck and De Mejia 2007). On the other hand, there are some medicinal uses that have not been confirmed by laboratory testing but are found to be traditionally used elsewhere for the treatment of health problems such as cold and flu
(Hilgert 2001), constipation (Small and Catling 2001), and headache (Filip et al. 2000). Additionally, our study highlighted a few perceived health benefits that have not yet been studied, such as alleviation of stomachache, treatment of pharyngitis, hydration properties, and prevention of urinary inflammation, although some studies suggest an anti-inflammatory activity of yerba maté (Luz et al. 2016). In contrast, there are some medicinal uses of yerba maté, such as cardiovascular protection, that are part of the tradition in South America (Kujawska 2018), but these were not reported in our study. The limited number of informants could be the reason behind the absence of such medical uses in our study.

Aromatic and medicinal herbs are sometimes added to yerba maté in South America (Kujawska 2018), as is the case in our study. The key difference in Syria is that in addition to medicinal purposes, economic factors are also drivers behind the use of such additives. Our study informants, similar to Paraguayan migrants living in Argentina (Kujawska 2018), have shown the use of several shared species such as Foeniculum vulgare Mill., Matricaria chamomilla L., Melilotus spp., Mentha spp., Rosmarinus officinalis L., Eriobotrya japonica (Thunb.) Lindl., Citrus spp., Ruta chalepensis L., and Aloysia citriodora Palau. However, it is not known if this pattern has independently occurred, or if it has been transferred with yerba maté culture from South America to Syria.

\section{Cross-Religious and Cross-Continental Comparison of Yerba Maté Consumption}

Members of the Alawite and Druze groups being the main consumers of yerba maté (Table 1), followed by Ismailis and Christians, respectively, may be associated with the conditions of minorities in Syria at the turn of the nineteenth and twentieth centuries (Talhamy 2010). These conditions pushed many of them to migrate to South America, and consequently adopt the yerba maté culture and carry it back with them upon their return to their homeland. The influence of place of residence on yerba maté consumption was obvious in the Alawite group, where drinkers in the diaspora consumed yerba maté much less than drinkers residing in Syria. On the other hand, yerba maté drinkers from the Ismaili and Druze communities showed similar consumption patterns regardless of place of residence. This may possibly reflect the conservatism of individuals in those groups with regard to 
preserving their cultural habits after changing their environment. Generally, yerba maté acts as an "identity preserver" and a nostalgia driver for many Syrians in the diaspora, as represented by several informants' statements. More than half of the respondents reported no change in their yerba maté consumption after they left their homeland, which attests to how the drink is rooted in their beverage culture. Similarly, Fischler (1988) highlighted food to be a fundamental element of cultural identity, and Fontefrancesco et al. (2019) illustrated how Albanian and Moroccan migrants in Italy consume their traditional food as a tool to go back to their origin, their childhood, and their national identity.

There was modest variation in yerba maté consumption between male and female respondents: men tend to drink more yerba maté ( 2.4 times more a week) than women do. The slight difference could be due to gender differences in preferences, prestige issues, or the weekly frequency of meetings with a group of people. Other studies have demonstrated a difference between genders regarding coffee consumption; for example, the study of Demura et al. (2013) reported that young men consumed coffee more than young women, with the taste of coffee being the main reason for the observed difference.

Yerba maté is consumed elsewhere in the Middle East, particularly by the Druze community in Mount Lebanon and the Israeli-occupied Syrian Golan Heights (Goldenberg 2002). Druze community members in the Eastern Mediterranean region, which was divided after the Sykes-Picot Agreement in 1916 into the current national borders, continued practicing the yerba maté culture since they underwent the same migration waves to South America at the end of the nineteenth century (Fildis 2011). On the other hand, although Poland is similar to Syria with regard to Polish migrants in South America, yerba maté consumption is not very common in Polish society. An exception is made by those who lived, or whose relatives lived, in South America. The main reason for this difference is that until 1989, when the Soviet Union collapsed and Poles took over the country's administration, free trade limitations and economic difficulties led to yerba maté not being a welcomed commodity. At that time, the Polish administration did not want any potential competition with the tea imported from China (Matero 2019).

Yerba maté consumption per capita is highest in Uruguay with 6-8 kg/person/year, followed by Argentina with $5 \mathrm{~kg} /$ person/year (Bracesco et al. 2011). In Paraguay, this figure is $2.5 \mathrm{~kg} /$ person/ year, while in Brazil it is $0.8 \mathrm{~kg} /$ person/year (Statista 2020). However, by dividing the amount of yerba maté imported to Syria in 2018 by 16.91 million, which was the population size that year (World Bank 2018), we find that annual individual consumption is approximately $2 \mathrm{~kg}$, while among the respondents in the present study it is $4.9 \mathrm{~kg} /$ person/year. This difference in the average consumption between our study respondents and the general Syrian population derives from two factors: the first is that we specifically targeted participants who drink yerba maté at least once per month. Second, we have included an equal number of participants from several religious groups that do not have equal distribution in the general population. One of these groups is the Sunni, representing the majority of the Syrian population, which showed the lowest consumption of yerba maté in the study.

The original yerba maté ritual has been slightly modified since being introduced into Syria by migrants returning from South America. Reports from $86 \%$ of respondents showed that when in a group, each person drinks yerba maté from his/her own glass, considering it better from a hygienic perspective. Whereas, in South America, yerba maté drinking is commonly done from the same vessel, which is usually made from a dried gourd of Lagenaria vulgaris Ser. (Small and Catling 2001). Syrians drink yerba maté only with hot water, whereas in South America, besides being drunk with hot water, yerba maté is also served with cold water (Tererê), especially during the hot summer days (Kujawska 2018).

\section{DifFerences in Consumption Patterns between Yerba Maté and Other Stimulant PlanTS}

Coffee and tea are the dominant plant stimulants in many countries. Coffee drinking is most popular in North America and Europe, where per capita consumption is higher than in Latin America, the region with the largest coffee production. Tea consumption prevails in South Asia, North Africa, Russia, and the British Isles. In South America, coffee is the dominant beverage except for some areas where yerba maté is drunk more than coffee (Grigg 2002). In Syria, as a part of the Middle East, coffee consumption started in the fifteenth century. Afterwards, tea replaced coffee as the leading beverage in the Middle East and North Africa (Grigg 2002). According to import data, as well as to our results, 
yerba maté has become the most preferred stimulant beverage in Syria. However, it is not easy to provide an explanation for these changes and contradictions. Beverage consumption changes significantly over time due to cultural, religious, market, and economic factors. Very similar is the case in Britain and Ireland where, in the year 1700 , coffee consumption was ten times that of tea, but by the middle of the eighteenth century, the British had become mainly tea drinkers (Smith 1996). The popularity of a new stimulant plant depends significantly on how a society's perception of the plant is built. For instance, khat has not been welcomed by local communities in the West. The main reason is that western media has emphasized that khat is an "addictive drug," and it has been confused with the consumption of other more potent stimulants like cocaine and MDMA. An additional reason why khat has not been welcomed is its association with cultural and religious stereotypes, especially in the last two decades, with the focus on the War on Terror (Carrier 2007).

Besides the previously mentioned factors leading to changes and adaptation to a new product, there are also different characteristics of each community, as well as the atmosphere provided when drinking a particular beverage. The social structure in Syria is characterized by strong family relationships and a lot of time spent together, and yerba maté provides an atmosphere suitable for long sessions. Coffee, on the other hand, is considered by many informants as a short-duration drink. Tea in Syria is associated mainly with breakfast or as a post-meal drink and it is rarely offered to visitors. According to OEC (2018a, 2018c), the import value of coffee and tea in Syria in 2018 was USD 45.90 million and USD 2.80 million, respectively. Whereas the import value of yerba maté in the same year was USD 71.70 million. This supports the results of our study regarding the preferred stimulant beverage in Syria. However, coffee, tea, and yerba maté prices are almost the same and go for around SP 10,000 (approximately USD 4.0) per $1 \mathrm{~kg}$. Therefore, it can be estimated that price does not influence a consumer's preference for one of these drinks over the others.

\section{Conclusion}

The present study contributes to the general understanding of yerba maté as an essential element of the Syrian beverage culture. Social and cultural factors are the leading causes of yerba maté popularity within the society, represented mainly by the social environment associated with this drink. The results indicate potential addiction as a hidden motive behind the regular consumption of yerba maté. A comparison between the studied culturalreligious groups showed that the Alawite and Druze groups consume yerba maté the most frequently. When compared to other stimulant drinks, yerba maté was the most prioritized, followed by coffee and tea. Future studies should address the social, ecological, and economic potential of introducing yerba maté cultivation in Syria.

\section{Supplementary Information}

The online version contains supplementary material available at https://doi.org/10.1007/s12231021-09523-6.

\section{Acknowledgments}

We would like to thank all study participants who shared with us their time and knowledge and two anonymous reviewers for their helpful comments on the manuscript. The study was funded by the Internal Grant Agency of the Faculty of Tropical AgriSciences, Czech University of Life Sciences Prague (IGA FTZ, Project No. 20213113). The authors declare that they have no conflict of interest. ZP, AP, and NS drafted the narrative. NS, AP, and RS designed the study. NS carried out the data collection, analyzed the data, and drafted the manuscript with major contributions from all the co-authors. AP, RS, CW, and ZP critically revised the manuscript. All authors read and approved the final manuscript version. The data that support the findings of this study are available from the corresponding author, upon reasonable request. The Code of Ethics of the International Society of Ethnobiology was rigorously followed, and informed consent was obtained prior to interviews. Participants were fully informed about the objectives and purpose of the proposed research. The question about religion was asked appropriately, respecting its sensitivity in the Syrian context.

\section{Literature Cited}

Aita, S. 2009. Labour markets performance and migration flows in SYRIA. Robert Schuman Centre for Advanced Studies. http://citeseerx.ist.psu.edu/ viewdoc/download?doi=10.1.1.472.2188\&rep= rep1\&type=pdf (20 December 2020). 
Arçari, D. P., W. Bartchewsky, T. W. dos Santos, K. A. Oliveira, A. Funck, J. Pedrazzoli, M. F. F. de Souza, M. J. Saad, D. H. M. Bastos, A. Gambero, P. D. O. Carvalho, and M. L. Ribeiro. 2009. Antiobesity effects of yerba maté extract (Ilex paraguariensis) in high-fat diet-induced obese mice. Obesity 17(12): 2127-2133.

Bernard, H. R. 2002. Research methods in anthropology: Qualitative and quantitative methods. Walnut Creek, California: Alta Mira Press.

Bouknight, S. 2018. Levantine love of yerba maté tells a 160-year Trans-Atlantic Tale, Part I. Inside Arabia. https://insidearabia.com/levantine-love-yerba-mate-tells-160-year-trans-atlantic-tale/ (20 December 2020).

Bracesco, N., A. G. Sanchez, V. Contreras, T. Menini, and A. Gugliucci. 2011. Recent advances on Ilex paraguariensis research: Minireview. Journal of Ethnopharmacology 136(3):378-384.

Braun, V. and V. Clarke. 2006. Using thematic analysis in psychology. Qualitative Research in Psychology 3(2):77-101.

Carrier, N. 2007. A strange drug in a strange land. In: Traveling cultures and plants: The ethnobiology and ethnopharmacy of human migrations, eds., A. Pieroni and I. Vandebroek, 186-203. New York, Oxford: Berghahn Books.

Demura, S., H. Aoki, T. Mizusawa, K. Soukura, M. Noda, and T. Sato, 2013. Gender differences in coffee consumption and its effects in young people. Food and Nutrition Sciences 4:748-757.

Dolores, M. and C. Tongco. 2007. Purposive sampling as a tool for informant selection. Ethnobotany Research \& Applications 5:147-158. https://doi.org/10.17348/era.5.0.147-158.

Fersan, E. 2010. Syro-Lebanese migration (1880 Present): "Push" and "pull" factors. Middle East Institute. https://www.mei.edu/publications/ syro-lebanese-migration-1880-present-pushand-pull-factors\#edn14 (21 December 2020).

Fildis, A. T. 2011. The troubles in Syria: Spawned by French divide and rule. Middle East Policy 18(4):129-139. https://doi.org/10.1111/j. 1475-4967.2011.00515.x.

Filip, M. S. R., S. B. Lotito, G. Ferraro, and C. G. Fraga. 2000. Antioxidant activity of Ilex paraguariensis and related species. Nutrition Research 20(10):1437-1446. https://doi.org/10. 1016/S0271-5317(00)80024-X.

Fischler, C. 1988. Food, self and identity. Social Science Information 27:275-292.

Folch, C. 2010. Stimulating consumption: Yerba mate myths, markets, and meanings from conquest to present. Comparative Studies in Society and History 52:6-36.

Fontefrancesco, M., C. Barstow, F. Grazioli, H. Lyons, G. Mattalia, M. Marino, A. E. McKay, R. Soukand, P. Corvo, and A. Pieroni. 2019. Keeping or changing? Two different cultural adaptation strategies in the domestic use of home country food plant and herbal ingredients among Albanian and Moroccan migrants in Northwestern Italy. Journal of Ethnobiology and Ethnomedicine 15, 11. https://doi.org/10. 1186/s13002-019-0290-7.

Gambero A. and M. Ribeiro. 2015. The positive effects of yerba maté (Ilex paraguariensis) in obesity. Nutrients 7(2):730-750. https://doi.org/ $10.3390 /$ nu7020730.

Glade, M. J. 2010. Caffeine-not just a stimulant. Nutrition 26(10):932-938. https://doi.org/10. 1016/j.nut.2010.08.004.

Goldenberg, D. 2002. Maté: A risk factor for oral and oropharyngeal cancer. Oral Oncology 38(7):646-649.

Görgen, M., K. Turatti, A. R. Medeiros, A. Buffon, C. D. Bonan, J. J. F. Sarkis, and G. S. Pereira. 2005. Aqueous extract of Ilex paraguariensis decreases nucleotide hydrolysis in rat blood serum. Journal of Ethnopharmacology 97(1):73-77.

Gorzalczany, S., R. Filip, M. D. R. Alonso, J. Miño, G. E. Ferraro, and C. Acevedo. 2001. Choleretic effect and intestinal propulsion of "mate" (Ilex paraguariensis) and its substitutes or adulterants. Journal of Ethnopharmacology 75(2-3):291294.

Grigg, D. 2002. The worlds of tea and coffee: Patterns of consumption. GeoJournal 57:283294.

Heck, C. I. and E. G. De Mejia. 2007. Yerba maté tea (Ilex paraguariensis): A comprehensive review on chemistry, health implications, and technological considerations. Journal of Food Science 72(9):138-152. https://doi.org/10.1111/j. 1750-3841.2007.00535.x.

Hilgert, N. I. 2001. Plants used in home medicine in the Zenta River basin, Northwest Argentina. Journal of Ethnopharmacology 76(1):11-34.

INYM. 2019. National Institution of Argentine yerba maté. https://www.inym.org.ar/serecuperan-las-exportaciones-y-el-consumointerno-mantiene-la-tendencia-positiva/ (21 December 2020).

ISE (International Society of Ethnobiology). 2006. International society of ethnobiology code of 
ethics (with 2008 additions). http://ethnobiology.net/code-of-ethics/ (22 December 2020).

Karpat, K. H. 1985. The "Syrian" emigration from the Ottoman state, 1870-1914. International Journal of Middle East Studies 17(2):175-209.

Kujawska, M. 2018. Yerba maté (Ilex paraguariensis) beverage: Nutraceutical ingredient or conveyor for the intake of medicinal plants? Evidence from Paraguayan folk medicine. Evidence-Based Complementary and Alternative Medicine 2018:6849317. https://doi. org/10.1155/2018/6849317.

Kukovecz, G. 1995. The Turks of Latin America: Remarks on the problem of Syrian-Lebanese emigration. Mediterrán tanulmányok 6:57-68.

Lesch, D. W. 2005. The new lion of Damascus: Bashar al-Asad and Modern Syria. New Haven, Connecticut: Yale University Press.

Luz, A. B. G., C. H. B. da Silva, M. V. P. S. Nascimento, B. M. C. Facchin, B. Baratto, T. S. Fröde, F. H. Reginatto, and E. M. Dalmarco. 2016. The anti-inflammatory effect of Ilex paraguariensis A. St. Hil (yerba maté) in a murine model of pleurisy. International Immunopharmacology 36:165-172. https:// doi.org/10.1016/j.intimp.2016.04.027.

Martin, G. J. 2014. Ethnobotany: A methods manual. Berlin: Springer-Science+Business Media, B.V.

Matero. 2019. The History of yerba maté in Poland. Available from: https://yerbamatero.com/ blogs/history/history-yerba-mate-poland (22 December 2020).

Mauri, M., T. Elli, G. Caviglia, G. Uboldi, M. Azzi. 2017. RAWGraphs: A visualisation platform to create open outputs. CHItaly '17: Proceedings of the 12th Biannual Conference on Italian SIGCHI Chapter. New York: Association for Computing Machinery. https://doi.org/10. $1145 / 3125571.3125585$.

Medeiros, P. M. D., G. T. Soldati, N. L. Alencar, I. Vandebroek, A. Pieroni, N. Hanazaki, and U. P. D. Albuquerque. 2012. The use of medicinal plants by migrant people: Adaptation, maintenance, and replacement. Evidence-Based Complementary and Alternative Medicine. 2012: 807452. https://doi.org/10.1155/2012/ 807452.

Obón, C., D. Rivera, F. Alcaraz, and L. Attieh. 2014. Beverage and culture. "Zhourat," a multivariate analysis of the globalization of an herbal tea from the Middle East. Appetite 79:1-10.
OEC (Observatory of Economic Complexity). 2018a. Coffee. https://oec.world/en/profile/ hs92/coffee (January 2021).

- 2018b. Maté. https://oec.world/en/profile/hs92/mate (January 2021).

- 2018c. Tea. https://oec.world/en/profile/ hs92/tea (January 2021).

Pieroni A. and I. Vandebroek. 2007. Traveling cultures and plants: The ethnobiology and ethnopharmacy of human migrations. New York, Oxford: Berghahn Books.

Pohler, H. 2010. Caffeine intoxication and addiction. The Journal for Nurse Practitioners 6(1): 49-52.

Salary Explorer. 2020. Average salary in Syria 2020. http://www.salaryexplorer.com/salary-survey. php?loc=211\&loctype $=1$ (22 December 2020).

Small, E. and P. M. Catling. 2001 . BLOSSOMING TREASURES OF BIODIVERSITY: 3. Maté (Ilex paraguariensis) - better than Viagra, marijuana, and coffee? Biodiversity 2(4):26-27.

Smith, S. D. 1996. Accounting for taste: British coffee consumption in historical perspective. Journal of Interdisciplinary History 27(2):183214.

de Souza, M. E. D. C. A., K. V. T. de Costa, and P. D. L. Menezes. 2018. Effect of caffeine on vestibular evoked myogenic potential: a systematic review with meta-analysis. Brazilian Journal of Otorhinolaryngology 84(3):381-388.

Statista. 2020. Annual per capita consumption of yerba maté in selected countries in Latin America as of July 2018. https://www.statista.com/ statistics/884925/consumption-yerba-mateper-capita-latin-america// (23 December 2020).

Swanson, J. A., J. W. Lee, and J. W. Hopp. 1994. Caffeine and nicotine: A review of their joint use and possible interactive effects in tobacco withdrawal. Addictive Behaviors 19(3):229-256.

Talhamy, Y. 2010. The Fatwas and the Nusayri/Alawis of Syria. Middle Eastern Studies 46(2):175-194.

Vandebroek, I., A. Pieroni, J. R. Stepp, N. Hanazaki, A. L. R. R. N. Alves, D. Picking, R. Delgoda, A. Maroyi, T. van Andel, C. L. Quave, N. Y. Paniagua-Zambrana, R. W. Bussmann, G. Odonne, A. M. Abbasi, U. P. Albuquerque, J. Baker, S. Kutz, S. Timsina, M. Shigeta, T. P. R. Oliveira, J. A. Hurrell, P. M. Arenas, J. P. 
Puentes, J. Hugé, Y. Yeşil, L. Jean Pierre, T. M. World Bank Open Data. 2018. Syrian Arab RepubOlango, and F. Dahdouh-Guebas. 2020. Reshaping the future of ethnobiology research after the COVID-19 pandemic. Nature Plants 6:723-730. https://doi.org/10.1038/s41477020-0691-6.

WFP. 2019. Country Brief. WFP, Damascus. https://docs.wfp.org/api/documents/WFP0000110324/download/ (23 December 2020). lic. https://data.worldbank.org/country/syrianarab-republic (23 December 2020).

Yasir, F., A. T. Wahab, and M. I. Choudhary. 2018. Protective effect of dietary polyphenol caffeic acid on ethylene glycol-induced kidney stones in rats. Urolithiasis 46:157-166.

Yerba maté Argentina. 2020. Yerba mate in the world. https://yerbamateargentina.org.ar/yerbamate/la-yerba-mate-en-el-mundo/ (20 December 2020). 